\title{
Responsivity Dependent Anodization Current Density of Nanoporous Silicon Based MSM Photodetector
}

\author{
Batool Eneaze B. Al-Jumaili, ${ }^{1,2}$ Zainal A. Talib, ${ }^{1}$ Asmiet Ramizy, ${ }^{2}$ Naser M. Ahmed, ${ }^{3}$ \\ L. Y. Josephine, ${ }^{1}$ Suriati B. Paiman, ${ }^{1}$ Ibrahim B. Muhd, ${ }^{1}$ and Sinan A. Abdulateef ${ }^{3}$ \\ ${ }^{1}$ Department of Physics, Faculty of Science, Universiti Putra Malaysia (UPM), 43400 Serdang, Selangor, Malaysia \\ ${ }^{2}$ Department of Physics, Anbar University, 31001 Anbar, Iraq \\ ${ }^{3}$ School of Physics, Universiti Sains Malaysia (USM), 11800 Penang, Malaysia \\ Correspondence should be addressed to Zainal A. Talib; zainalat@upm.my
}

Received 20 June 2016; Revised 5 September 2016; Accepted 14 September 2016

Academic Editor: Christian Brosseau

Copyright (C) 2016 Batool Eneaze B. Al-Jumaili et al. This is an open access article distributed under the Creative Commons Attribution License, which permits unrestricted use, distribution, and reproduction in any medium, provided the original work is properly cited.

\begin{abstract}
Achieving a cheap and ultrafast metal-semiconductor-metal (MSM) photodetector (PD) for very high-speed communications is ever-demanding. We report the influence of anodization current density variation on the response of nanoporous silicon (NPSi) based MSM PD with platinum (Pt) contact electrodes. Such NPSi samples are grown from n-type Si (100) wafer using photoelectrochemical etching with three different anodization current densities. FESEM images of as-prepared samples revealed the existence of discrete pores with spherical and square-like shapes. XRD pattern displayed the growth of nanocrystals with (311) lattice orientation. The nanocrystallite sizes obtained using Scherrer formula are found to be between $20.8 \mathrm{~nm}$ and $28.6 \mathrm{~nm}$. The observed rectifying behavior in the $I-V$ characteristics is ascribed to the $\mathrm{Pt} / \mathrm{PSi} / \mathrm{n}-\mathrm{Si}$ Schottky barrier formation, where the barrier height at the Pt/PSi interface is estimated to be $0.69 \mathrm{eV}$. Furthermore, this Pt/PSi/Pt MSM PD achieved maximum responsivity of $0.17 \mathrm{~A} / \mathrm{W}$ and quantum efficiency as much as $39.3 \%$. The photoresponse of this NPSi based MSM PD demonstrated excellent repeatability, fast response, and enhanced saturation current with increasing anodization current density.
\end{abstract}

\section{Introduction}

Canham's [1] discovery on the room temperature visible photoluminescence (PL) from porous silicon (PSi) generated intense research interests towards the synthesis and characterization of $\mathrm{Si}$ nanostructures (NSs) in general and nanoporous silicon (NPSi) in particular. These spectra of research activities are mainly targeted to achieve Si nanomaterials with desired band gap useful for efficient optoelectronic applications [2-4]. Over the years, various promising electroluminescent devices are fabricated $[5,6]$. Nanosilicon research is triggered not only because of technological implication but also to unravel the fundamental mechanism, socalled quantum confinement effect, which is responsible for the energy band gap enhancement $[7,8]$. Porous silicon (PSi) exhibits several notable attributes including direct and wide modulated energy band gap, high resistance, large surfaceto-volume ratio, and identical single-crystalline structure as bulk Si. These properties are beneficial for making photodetectors $[9,10]$.

Earlier, different types of solid-state PDs are fabricated such as the p-n junction, MSM structure, and Schottky diodes. Among all these, MSM PDs received special attention due to their easy fabrication and integration flexibility. Planar PSi MSM PDs are already fabricated without rapid thermal oxidation (RTO) treatment [10, 11], where the finger contacts are made using a micromachined Si mask. Tsai et al. [12] fabricated the Si p-n junction PD with a subsequent RTO PSi antireflection cap layer. Lee et al. $[13,14]$ claimed that the RTO and Rapid Thermal Annealing (RTA) treatments to PSi MSM PD can enhance the photoresponsivity and reduce the dark current significantly. This reduction in the dark current is attributed to the annealing assisted formation of an oxide between the metal and semiconductor layer. Creation of high-performance MSM PDs requires 
a large Schottky barrier height at the metal semiconductor interface, leading to a small leakage current and high breakdown voltage. This improves the responsiveness in terms of photocurrent to dark current ratio. Generally, to achieve a large Schottky barrier height on $\mathrm{Si}$ and PSi, one selects the metals with high work functions such as gold $(\mathrm{Au})$, platinum $(\mathrm{Pt})$, palladium $(\mathrm{Pd})$, and nickel $(\mathrm{Ni})$. However, most of these outperforming metals are unstable at high temperature due to severe interdiffusion at the metalsemiconductor interface [15]. Platinum, being an interesting functional metal with excellent thermal and chemical properties, is extensively used as a stable Schottky contact in wide band gap InGaN [16].

Considering the prospect of NPSi in MSM PD, we fabricated a Pt/PSi/Pt PD and determined its photoresponse as well as $I-V$ characteristics. Low cost nanocrystalline PSi samples are synthesized in the absence of thermal oxidation treatment. The effects of variable anodization current density on the morphology, structure, and PL properties of such NPSi structures are evaluated.

\section{Experimental Methods}

Phosphorus doped crystalline n-type $\mathrm{Si}$ (100) substrates (resistivity, $\sim 1$ to $10 \Omega \cdot \mathrm{cm}$ ) are etched via photoelectrochemical reaction in the presence of continuous illumination at varying anodization current density to grow NPSi. At first, these $\mathrm{Si}$ substrates are cleaned via wet chemical etching (RCA cleaning method). Then, two-electrode setup is applied including $\mathrm{Si}$ as anode and Pt mesh as cathode. Next, these crystalline Si wafers are anodized in a 1:4 solution $(48 \% \mathrm{HF}$ to ethanol) for $15 \mathrm{~min}$ at changing anodization current density such as 20,25 , and $35 \mathrm{~mA} / \mathrm{cm}^{2}$ under constant illumination (halogen lamp with $50 \mathrm{~W}$ power placed at a distance of $15 \mathrm{~cm}$ from the sample). Finally, the MSM diode is fabricated via samples metallization, where finger-shaped Pt electrodes (metal contacts of $200 \mathrm{~nm}$ thickness) are deposited on the top of NPSi specimen using A500 Edward radio frequency magnetron sputtering system. In the present study, $\mathrm{Pt}$ is used for Schottky contact due to its high value of work function. The structure of MSM photodetector is comprised of a pair of interdigitated Schottky contacts (electrodes), where each electrode has four fingers having width of $230 \mu \mathrm{m}$ and spacing of $400 \mu \mathrm{m}$ and length of each electrode is about $3.3 \mathrm{~mm}$. The two sets of finger electrodes are identical. The percentage of covered area (Schottky contact) is $1.5 \times 10^{-4} \mathrm{~cm}^{2}$ and the irradiated area of the device is $0.784 \mathrm{~cm}^{2}$. The morphology of the NPSi samples is analyzed using field emission scanning electron microscopy (FESEM, JSM-7600F). Samples crystallinity is verified using X-ray diffraction (PANalytical X'Pert PRO). Raman measurement is performed (WITec) to examine the vibrational modes. PL spectra are recorded using a Perkin-Elmer LS-55 spectrophotometer. The electrical properties of the developed MSM PD are examined via Keithley Model 4200-SCS instrument. The photoelectric response is evaluated using a $460 \mathrm{~nm}$ wavelength pulsed LED operated at the intensity of $7 \mathrm{~W} / \mathrm{cm}^{2}$.

\section{Results and Discussion}

3.1. Morphological and Structural Characterization of NPSi. FESEM images in Figure 1 display the anodization current density dependent morphological evolution of the grown PSi samples. Figures 1(a)-1(c) illustrate the top views of the three samples and the corresponding cross-sectional views are presented in Figures 1(d)-1(f). They showed regular columns of Si nanocrystal with pores (hole) in between. It is clear that the sample morphology is highly sensitive to the change in etching current. Figure 1(a) revealed nonuniform pores with decrease in the pore density. The cross-sectional view (Figure $1(\mathrm{~d})$ ) showed the occurrence of nonparallel and partially cracked silicon walls, which caused narrow and asymmetrical holes between them. Sample grown at $25 \mathrm{~mA} / \mathrm{cm}^{2}$ anodization current density (Figure 1(b)) displayed substantially wider pores, which are irregular across the entire surface. The cross-sectional view (Figure 1(e)) indicated an increase in the thicknesses up to $37.1 \mu \mathrm{m}$. Sample grown at $35 \mathrm{~mA} / \mathrm{cm}^{2}$ anodization current density (Figure 1(c)) exhibited highly porous nature with columnar structure, which is uniform across the entire surface. The cross-sectional view (Figure 1(f)) demonstrates that the silicon walls can be distinguished from the sharp pin-shaped holes with lengths of up to $48 \mu \mathrm{m}$ inside the silicon substrate. Furthermore, an increase in the anodization current density is found to reduce the size of columns of Si nanocrystal.

Figure 2 illustrates the XRD patterns of three PSi samples and the inset signifies the corresponding bulk Si pattern. The occurrence of sharp and dominant peak at $56.13^{\circ}$ corresponds to the growth along (311) lattice plane. In addition, a weak peak located at $47.5^{\circ}$ corresponding to the diffraction peaks of Si from (220) is observed. All the prepared samples revealed prominent growth peak along (311) orientation at $56.14^{\circ}$ (grown at $20 \mathrm{~mA} / \mathrm{cm}^{2}$ ), $56.15^{\circ}$ (grown at $25 \mathrm{~mA} / \mathrm{cm}^{2}$ ), and $56.17^{\circ}$ (grown at $35 \mathrm{~mA} / \mathrm{cm}^{2}$ ). This peak clearly verified the existence of nanocrystals in the PSi samples. Scherrer formula [17] is used to calculate the crystallite sizes, which are found to be $28.6 \mathrm{~nm}, 26.8 \mathrm{~nm}$, and $20.8 \mathrm{~nm}$ for samples grown at current density of $20 \mathrm{~mA} / \mathrm{cm}^{2}, 25 \mathrm{~mA} / \mathrm{cm}^{2}$, and $35 \mathrm{~mA} / \mathrm{cm}^{2}$, respectively. The broadening of XRD peak is attributed to the effect of size confinement [12]. The XRD results are in agreement with the FESEM analyses.

Figure 3 shows the room temperature Raman spectra of all the samples. Samples grown at anodization current density of 20,25 , and $35 \mathrm{~mA} / \mathrm{cm}^{2}$ displayed significant Raman peaks centered at $516 \mathrm{~cm}^{-1}, 514 \mathrm{~cm}^{-1}$, and $511 \mathrm{~cm}^{-1}$, respectively. These peaks are allocated to the Si-Si optical phonon mode for NPSi structures. In crystalline bulk Si, due to the conservation of quasi momentum, the optical phonon peak appears at $520.2 \mathrm{~cm}^{-1}$. A decrease in the nanocrystallite size at higher anodization current shifted the optical phonon peak towards the lower frequency which is in conformity with the XRD and FESEM results. Moreover, these peaks are broadened and appeared to be more intense [18]. The observed shift in the Raman peak is attributed to the reduction in the phonon energy aroused from the disturbances in the NPSi lattice structure. 


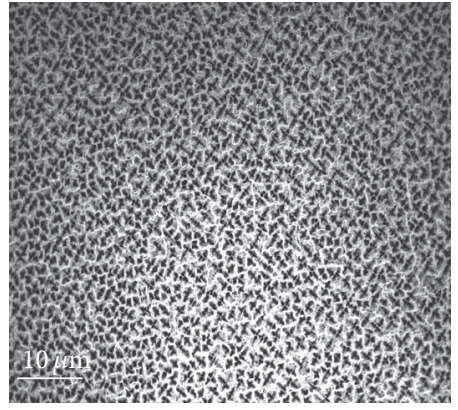

(a)

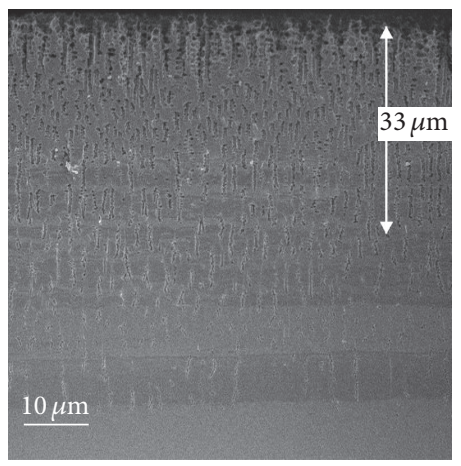

(d)

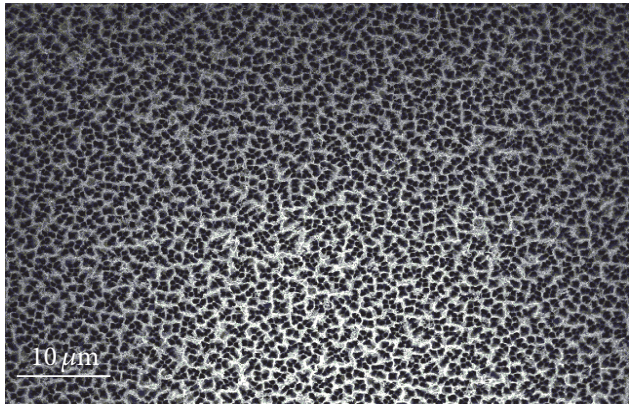

(b)

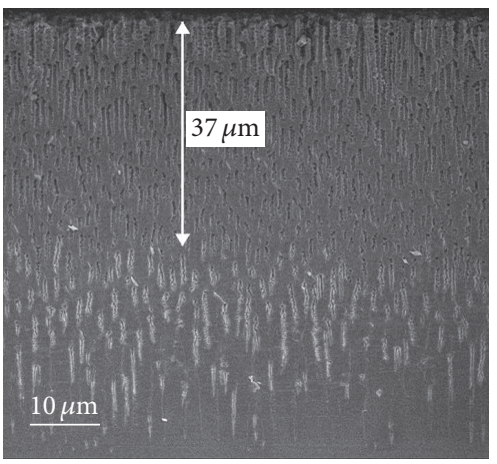

(e)

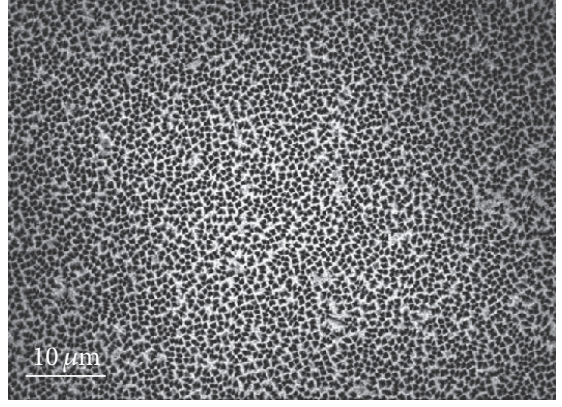

(c)

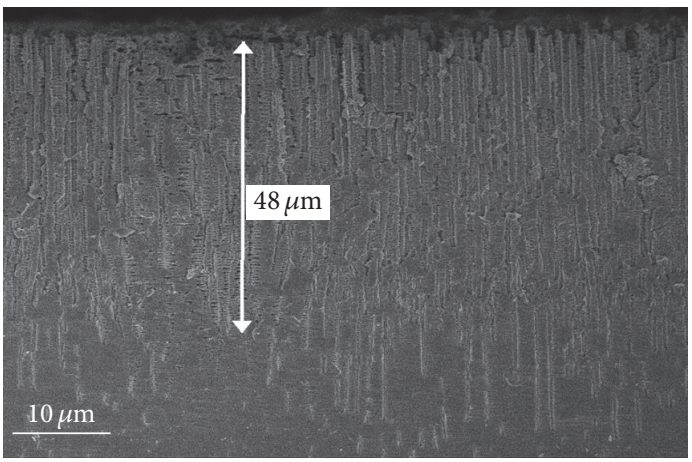

(f)

FIGURE 1: FESEM images of the NPSi obtained at variance anodization current density: top view of (a) $20 \mathrm{~mA} / \mathrm{cm}^{2}$, (b) $25 \mathrm{~mA} / \mathrm{cm}^{2}$, and (c) $35 \mathrm{~mA} / \mathrm{cm}^{2}$. Cross section of (d) $20 \mathrm{~mA} / \mathrm{cm}^{2}$, (e) $25 \mathrm{~mA} / \mathrm{cm}^{2}$, and (f) $35 \mathrm{~mA} / \mathrm{cm}^{2}$.

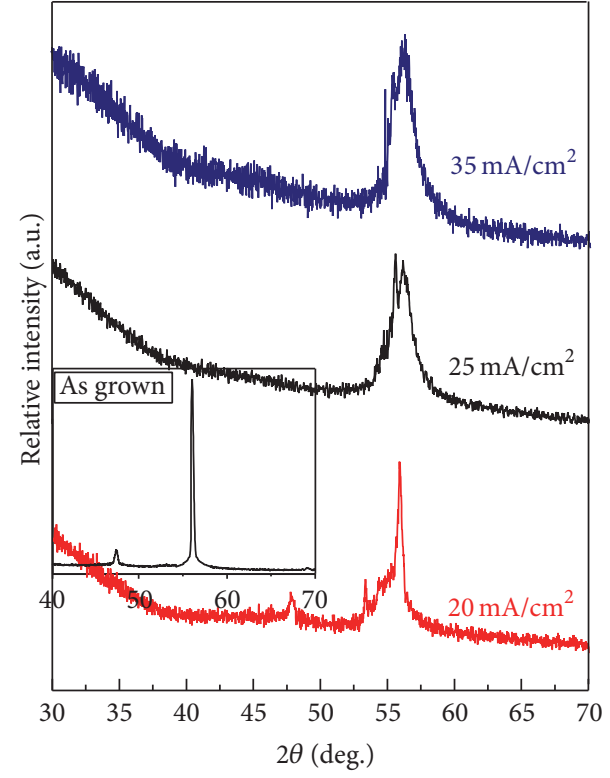

FIGURE 2: XRD patterns of NPSi samples grown at various anodization current densities: $20 \mathrm{~mA} / \mathrm{cm}^{2}, 25 \mathrm{~mA} / \mathrm{cm}^{2}$, and $35 \mathrm{~mA} / \mathrm{cm}^{2}$.

3.2. Photoluminescence Spectra. Figure 4 depicts the room temperature PL spectra of samples etched at different current densities. The observed blue shift in the PL peak with the increase of the anodization current originated from quantum

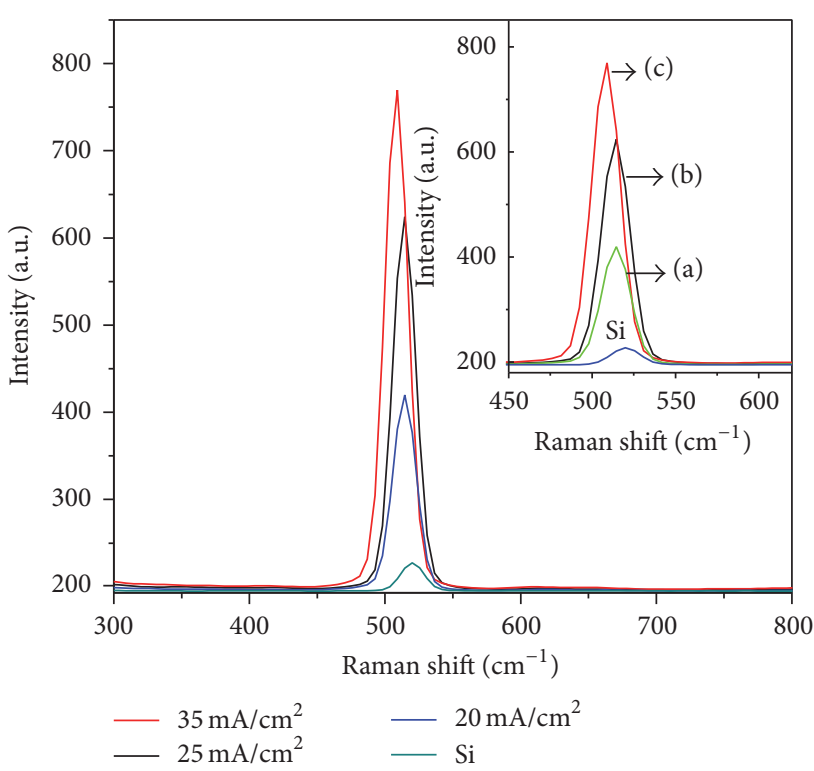

FIgURE 3: Raman spectra of NPSi synthesized at different anodization current density, (a) $20 \mathrm{~mA} / \mathrm{cm}^{2}$, (b) $25 \mathrm{~mA} / \mathrm{cm}^{2}$, and (c) $35 \mathrm{~mA} / \mathrm{cm}^{2}$, and bulk Si.

confinement effect signified an enhancement in the energy band gap of as much as $2.06 \mathrm{eV}$. A reduction in the FWHM for the peak is evidenced with the increase in the anodization current from 20 to $35 \mathrm{~mA} / \mathrm{cm}^{2}$. Furthermore, the increase 


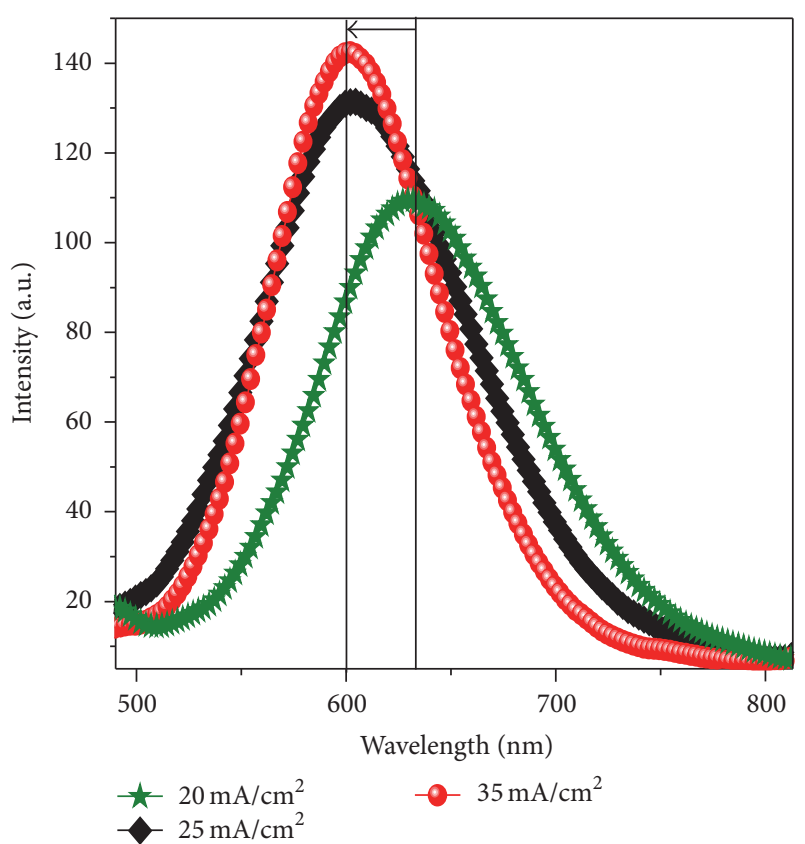

FIGURE 4: PL spectra of PSi samples at room temperature for anodization current of $20 \mathrm{~mA} / \mathrm{cm}^{2}, 25 \mathrm{~mA} / \mathrm{cm}^{2}$, and $35 \mathrm{~mA} / \mathrm{cm}^{2}$.

in PL intensity with the increase of anodization current is due to the enhanced recombination probability of the carriers in the strongly confined nanostructure, where the nature of the band gap is transformed from indirect one to quasidirect one [17]. These observations related to PL peak shift, narrowing of FWHM, and increase in the peak intensity are in good agreement with other findings $[19,20]$. The observed Sband luminescence is reported to occur within 400-800 nm [19]. It is asserted that the increase in samples porosity and enhancement in the PL intensity and the blue shift with increasing anodization current are strongly correlated. Thus, the variation in the anodization current and etching time duration strongly affected the PL properties of synthesized NPSi [19-21].

3.3. Current-Voltage Characteristics. Figure 5 demonstrates the $I-V$ characteristics of Pt/NPSi planer system under ambient light illumination as a function of varying anodization current. When a metal and a semiconductor with no surface states are brought in contact with each other at equilibrium, their Fermi levels get aligned. This alignment of Fermi levels is due to the charge motion from the higher energy side towards the lower energy side, resulting in the creation of a depletion region in the semiconductor and a barrier on the interface [22]. So, the observed rectifying behavior of the planer system is attributed to the formation of Schottky barrier at Pt/PSi interface, which controls the current conduction as well as the capacitance. The forward bias characteristics of the samples are controlled by the resistance of PSi layer, which is responsible for the reduction of current flow with increasing anodization current [20]. Increased porosity with increase in the anodization current leads to the formation of regular columns (Si nanocrystal) and pores (hole). Thus, the

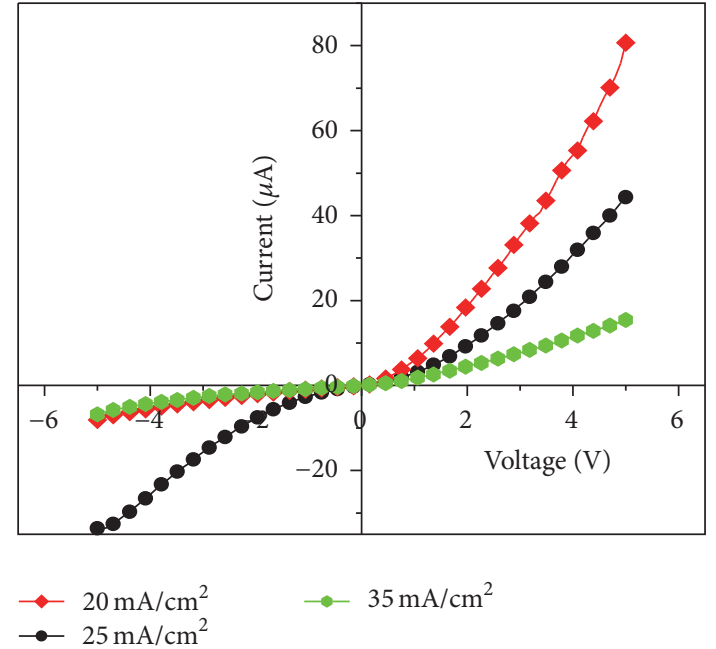

FIgURE 5: $I-V$ characteristics of Pt contact created above the NPSi samples prepared at anodization current at $20 \mathrm{~mA} / \mathrm{cm}^{2}, 25 \mathrm{~mA} / \mathrm{cm}^{2}$, and $35 \mathrm{~mA} / \mathrm{cm}^{2}$ under ambient light illumination.

surface area becomes larger and contains a high density of donor-like surface state acting as carriers trap, thereby reducing the current flow in the porous PSi layer. Generally, the sensitivity of the MSM PDs gets enhanced with the increase of bias voltage. However, in the present case, the current is found to be nearly constant to the light at smaller bias voltages $\left(V_{\text {bias }}<0.5 \mathrm{~V}\right)$. This observation is attributed to the $\mathrm{Pt} / \mathrm{PSi} / \mathrm{n}-\mathrm{Si}$ space charge region mediated restricted current flow in the MSM structure. However, in the higher voltage zone, the PSi absorbs light to produce more $\mathrm{e}-\mathrm{h}$ pairs within the space charge region. The existence of the electrical field within the space charge region resulting from an applied high bias voltage led to the separation of the charge carriers, which created an upward surge in thermionic emission and carrier velocity. Consequently, the current is exponentially increased with the applied voltage which exceeded the potential barrier. The bias voltage provided sufficient energy to the electron to break the barrier height and generated strong diffusion current $[11,20]$ by drifting the holes and the electrons to the positive and negative sides, respectively. This mechanism is responsible for the generation of the photocurrent in the exterior contact. Besides, the inflow of electrons within the circuit transformed the optical signals to electrical signals; thus the PD is successfully implemented.

This result clearly demonstrates the influence of anodization current densities on the $I-V$ characteristics of MSM devices, in which the sample prepared at $35 \mathrm{~mA} / \mathrm{cm}^{2}$ reveals a very low current in comparison to other samples. This observation is attributed to the high resistivity and Schottky barrier height of the proposed photodetector. Meanwhile, the sample prepared at $25 \mathrm{~mA} / \mathrm{cm}^{2}$ displayed the highest leakage current which may arise from other current transport mechanisms. In fact, if the thermionic emission over the barrier is neglected, then the current transport mechanism may include the direct tunneling of carriers [16]. Meanwhile, the sample prepared at $35 \mathrm{~mA} / \mathrm{cm}^{2}$ showed lowest value of 


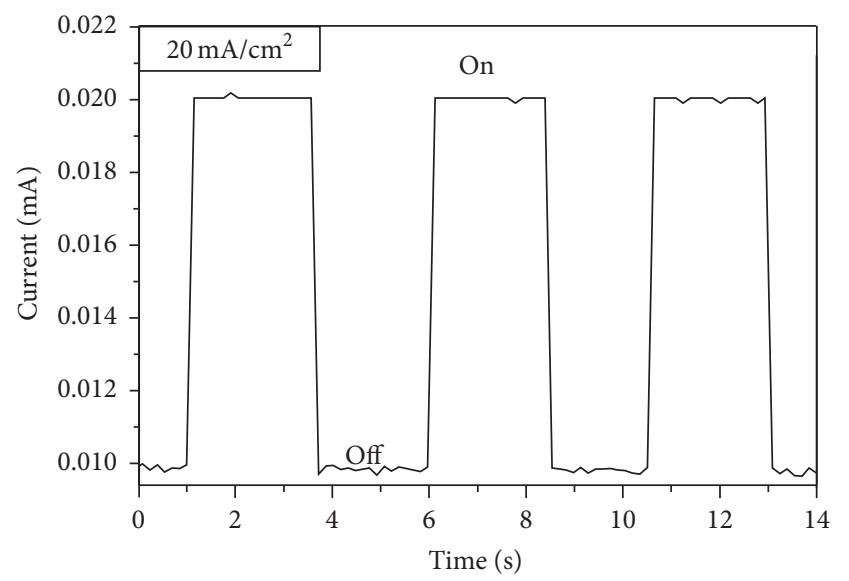

(a)

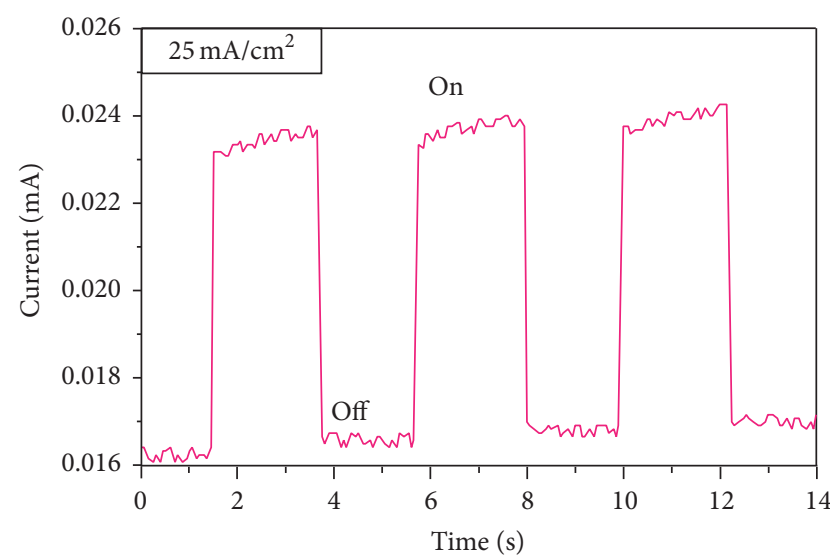

(b)

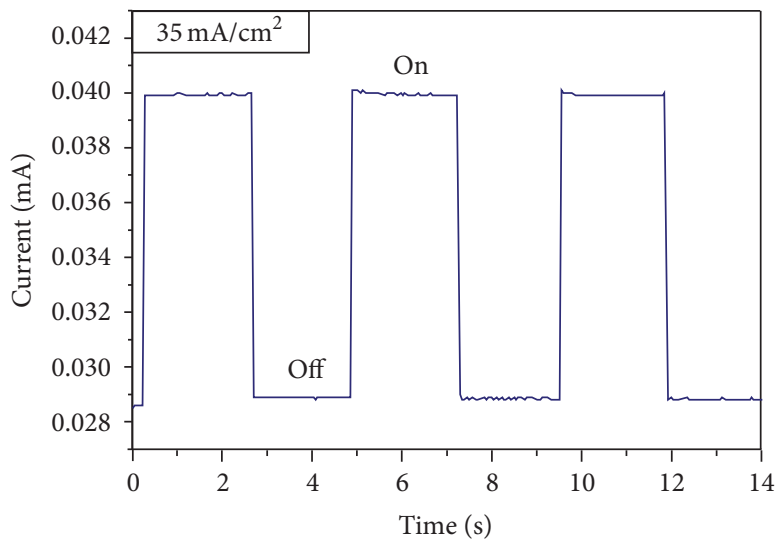

(c)

Figure 6: Repetitive switching of the Pt/NPSi photodetectors under blue light ( $460 \mathrm{~nm}$ ) at $2 \mathrm{~V}$ applied across two electrodes of (a) $20 \mathrm{~mA} / \mathrm{cm}^{2}$, (b) $25 \mathrm{~mA} / \mathrm{cm}^{2}$, and (c) $35 \mathrm{~mA} / \mathrm{cm}^{2}$.

leakage current, indicating that the electrical properties are improved.

Fundamentally, the value of Schottky barrier height and the ideality factor decide the outperforming nature of electronic devices. Structurally, MSM consists essentially of two Schottky contacts connected back-to-back with one another. The arrangement for the contacts allows for reverse bias and forward bias under a biasing voltage from $-5 \mathrm{~V}$ to $+5 \mathrm{~V}$. Following the thermionic emission-diffusion theory, the expression for the Schottky barrier height $\left(\Phi_{B}\right)$ and the ideality factor $(n)$ is written as $[11,23]$

$$
\begin{aligned}
I & =I_{0} \exp \left[\frac{q v}{n K_{B} T}\right], \\
I_{0} & =A^{*} A T^{2} \exp \left[\frac{-q \Phi_{B}}{K_{B} T}\right],
\end{aligned}
$$

where $I_{0}$ is the saturation anodization current density, $T$ is the temperature, $K_{B}$ is Boltzmann constant, $A^{*}$ is the effective Richardson coefficient, $A$ is the area of the Schottky contact $\left(1.5 \times 10^{-4} \mathrm{~cm}^{2}\right)$, and $q$ is the electronic charge.

The intercept of $\ln I \sim V$ curve is used to calculate the value of $\Phi_{B}$. Table 1 summarizes the estimated values of $\Phi_{B}, I_{0}$, and $n$ for all the samples. The alteration in $\Phi_{B}$ values at different current densities is attributed to the surface roughening, which played a significant role in the interface between the porous Si surface and the metal, leading to the enhancement of the electrical properties [24]. The high porosity at large anodization current density is ascribed to responsibility for the increase of $\Phi_{B}$, which led the Fermi level to shift towards the valence band and decrease in the leakage current [24]. These proportionately large values of the ideality factor may be correlated to the higher density of interface states [25]. It is acknowledged that the presence of two heterojunctions in samples such as the one in the substrate-porous Si interface and the other within the porous $\mathrm{Si}$ and $\mathrm{Pt}$ is responsible for the enhancement of $n$ [26]. In addition, the occurrence of inhomogeneous barrier height can make $n$ large as reported earlier [20].

3.4. Photocurrent and Light Responsivity. Repeatability of the fabricated PSi MSM PDs is examined by measuring the photoresponse. The dynamic responsivity time is measured by illuminating the PDs with chopped blue light $(460 \mathrm{~nm}$ at $7 \mathrm{~W} / \mathrm{cm}^{2}$ ) at bias voltage of $2 \mathrm{~V}$. Figure 6 shows the repetitive switching of the blue light for the fabricated PDs at $2 \mathrm{~V}$ 
TABLE 1: Etching current density dependent Schottky barrier height, ideality factor, and saturation current of Pt/NPSi system.

\begin{tabular}{lccc}
\hline $\begin{array}{l}\text { Anodization } \\
\text { current density } \\
\left(\mathrm{mA} / \mathrm{cm}^{2}\right)\end{array}$ & $\Phi_{B}(\mathrm{eV})$ & $n$ & Saturation current $(\mathrm{A})$ \\
\hline 20 & 0.67 & 4.6 & $1.2 \times 10^{-7}$ \\
25 & 0.68 & 5.1 & $1.9 \times 10^{-7}$ \\
35 & 0.69 & 4.1 & $2.5 \times 10^{-7}$ \\
\hline
\end{tabular}

for the NPSi samples grown at anodization current density. The photocurrent is found to be stable and repeatable in each on/off period. The response time at various anodization current of 20,25 , and $35 \mathrm{~mA} / \mathrm{cm}^{2}$ is achieved to be $35 \mathrm{~ms}$, $30 \mathrm{~ms}$, and $20 \mathrm{~ms}$, respectively, whereas the recovery time is discerned to be $40 \mathrm{~ms}, 44 \mathrm{~ms}$, and $37 \mathrm{~ms}$, respectively.

The response time and recovery time of the PSi, especially for the sample prepared at $35 \mathrm{~mA} / \mathrm{cm}^{2}$, revealed the shortest value as compared to those achieved by others [27-30]. The maximum response that is obtained at high anodization current (high porosity) is attributed to the defects-free state, good quality, and big photoactive surface areas of the samples. The fast response is associated with the short transit time of photogenerated carriers with long lifetime [29], whereas the slow response time corresponded to the presence of grain boundaries and the oxygen adsorption at the surface [31], as verified by other findings [20].

The light responsivity $(R)$ is the important parameter that sets the photovoltaic sensitivity of devices, which is defined by the photocurrent $\left(I_{\mathrm{ph}}\right)$ produced for every unit power of incident light $\left(P_{\text {inc }}\right)$ on the active area $(A)$ of the PDs and expressed as [30]

$$
R=\frac{I_{\mathrm{ph}}(\mathrm{A})}{P_{\mathrm{inc}}(\mathrm{W})}=\frac{I_{\mathrm{ph}}(\mathrm{A})}{E\left(\mathrm{~W} / \mathrm{cm}^{2}\right) A\left(\mathrm{~cm}^{2}\right)},
$$

where $E$ is the energy of Xenon radiation source measured using standard photometer.

Figure 7 illustrates the anodization current dependent room temperature photoresponse of $\mathrm{Pt} / \mathrm{PSi} / \mathrm{n}-\mathrm{Si} \mathrm{PD}$. The responsivity spectra are comprised of two main visible peaks centered at $530 \mathrm{~nm}$ and $765 \mathrm{~nm}$. The light responsivity of the $\mathrm{PD}$ devices is measured in the wavelength range of 300$900 \mathrm{~nm}$ under $5 \mathrm{~V}$ bias voltages. The overall responsivity of PSi is found to improve with increasing anodization current density. The measured values of responsivity are $0.053,0.12$, and $0.17 \mathrm{~A} / \mathrm{W}$ at $530 \mathrm{~nm}$ for anodization current densities of 20,25 , and $35 \mathrm{~mA} / \mathrm{cm}^{2}$, respectively. This alteration in the light responsivity is attributed to the change in the thickness of the active area and the contact coverage of samples [20]. The maximum response is attained for thick sample with high porosity.

The value of peak responsivity of n-type PSi based MSM $\mathrm{PD}$ fabricated by photoelectrochemical etching is $0.17 \mathrm{~A} / \mathrm{W}$ at the wavelength of $530 \mathrm{~nm}$. This is much higher (170 times) than the one reported for PSi MSM structures [32, 33] for different $\mathrm{p}$-type PSi fabrication via electrochemical etching. The observed intense peak at $530 \mathrm{~nm}$ originated from the upper

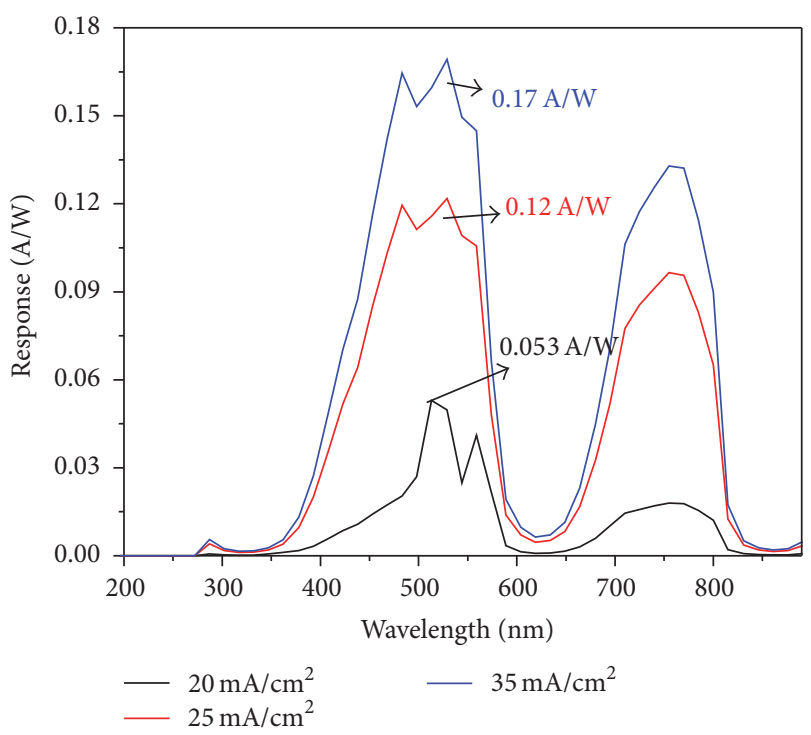

FIGURE 7: Photoresponse of Pt/NPSi as a function of the wavelength for MSM device prepared at anodization current of $20 \mathrm{~mA} / \mathrm{cm}^{2}$, $25 \mathrm{~mA} / \mathrm{cm}^{2}$, and $35 \mathrm{~mA} / \mathrm{cm}^{2}$.

platinum contacts, which is also observed in Au-Si device [34]. The relatively weaker peak at $765 \mathrm{~nm}$ emerged from $\mathrm{PS} / \mathrm{Si}$ junction [33]. The enhancement of light responsiveness at lower wavelength is due to the increase in photocurrent as shown in (2), where an increase in the porosity at higher anodization current generated large number of $\mathrm{e}-\mathrm{h}$ pairs in the depletion region. This is expected because the penetration depth gets reduced with the wavelength, thereby lowering the photons absorption in the Si substrate and simultaneously enhancing the depletion region. Thus, the number of $\mathrm{e}-\mathrm{h}$ pairs generated in the depletion region is increased with the reduction of wavelength. Further observation revealed that the light responsivity is reduced sharply at smaller wavelength (blue and near UV). This is confirmed by the absorption of photons in the PSi film, negating its arrival at the depletion region [9], which is consistent with other reports [35].

The performance of the developed photosensitive device is evaluated in terms of quantum efficiency $(\eta)$, which is correlated with the number of electron-hole pairs that are excited by the absorbed photons and given by [30]

$$
\eta=R \times \frac{h c}{q \lambda}
$$

where $\lambda$ is the wavelength of incident light, $h$ is the Plank constant, and $c$ is the velocity of light.

The quantum efficiency of the designed PSi photodiodes is discerned to be $12.3 \%, 28.3 \%$, and $39.5 \%$ for the current densities of 20,25 , and $35 \mathrm{~mA} / \mathrm{cm}^{2}$, respectively. This observation is similar to the one reported in Ag/PSi Schottky PDs using alternative current to anodization PSi [20]. It is found that the responsivity of such MSM photodiode can reach $0.5 \mathrm{~A} / \mathrm{W}$. The occurrence of large responsivity with quantum efficiency of as much as $99.5 \%$ clearly indicated the existence of internal gain in this photodiode. It is acknowledged that the large responsivity and the observed internal gain 
are originated from the defects in their PSi film or from metal/semiconductor interfaces [20]. Besides, the spectral evolution as a function of etching current density appeared to be identical to those of spectral responsivity.

\section{Conclusions}

The effects of changing anodization current densities on the performance of NPSi based MSM PD are examined. These PDs are successfully fabricated by metallization of NPSi and their photoresponse in the visible region is evaluated. It is demonstrated that the anodization current density significantly controlled the pore density and the spectral responsivity. The synthesized NPSi samples are of good quality. They exhibited strong PL peak accompanied by a large blue shift, which indicated the existence of the high regularity and large porosity of this surface. Nature of this surface is established to be responsible for decreasing the Si crystallite size at higher anodization current density. For this fabricated PDs, we achieved good stability over time, great responsivity, fast response, and quick recovery time. It is asserted that the efficiency of the proposed PDs can be further improved by controlling the etching current density. Our systematic method of sample preparation, PDs fabrication, and characterization may constitute a basis for the development of NPSi based MSM PDs.

\section{Competing Interests}

The authors declare that they have no competing interests.

\section{Acknowledgments}

This work was supported by the Ministry of Higher Education Malaysia under Research University Grant Scheme (Grant no. GP-IPB/2014/9449900) and the Ministry of High Education and Scientific Research of Iraq.

\section{References}

[1] L. T. Canham, "Silicon quantum wire array fabrication by electrochemical and chemical dissolution of wafers," Applied Physics Letters, vol. 57, no. 10, pp. 1046-1048, 1990.

[2] R. L. Smith and S. D. Collins, "Porous silicon formation mechanisms," Journal of Applied Physics, vol. 71, no. 8, pp. R1R22, 1992.

[3] U. Rossow, "Optical characterization of porous materials," Physica Status Solidi (A), vol. 184, no. 1, pp. 51-78, 2001.

[4] N. Jeyakumaran, B. Natarajan, N. Prithivikumaran, S. Ramamurthy, and V. Vasu, "Structural and optical properties of n-type porous silicon: effect of Light Illuminiation," Surface Review and Letters, vol. 15, no. 6, pp. 897-901, 2008.

[5] L. Stalmans, J. Poortmans, H. Bender et al., "Porous silicon in crystalline silicon solar cells: a review and the effect on the internal quantum efficiency," Progress in Photovoltaics: Research and Applications, vol. 6, no. 4, pp. 233-246, 1998.

[6] P. M. Fauchet, J. von Behren, K. D. Hirschman, L. Tsybeskov, and S. P. Duttagupta, "Porous silicon physics and device applications: a status report," Physica Status Solidi (A), vol. 165, no. 1, pp. 3-13, 1998.
[7] V. Lehmann and U. Gösele, "Porous silicon formation: a quantum wire effect," Applied Physics Letters, vol. 58, no. 8, pp. 856-858, 1991.

[8] L. Pavesi, R. Guardini, and P. Bellutti, "Porous silicon n-p light emitting diode," Thin Solid Films, vol. 297, no. 1-2, pp. 272-276, 1997.

[9] T. Hadjersi and N. Gabouze, "Photodetectors based on porous silicon produced by Ag-assisted electroless etching," Optical Materials, vol. 30, no. 6, pp. 865-869, 2008.

[10] L. A. Balagurov, S. C. Bayliss, S. Y. Andrushin et al., "Metal/PS/cSi photodetectors based on unoxidized and oxidized porous silicon," Solid-State Electronics, vol. 45, no. 9, pp. 1607-1611, 2001.

[11] A. F. Abd Rahim, M. R. Hashim, and N. K. Ali, "High sensitivity of palladium on porous silicon MSM photodetector," Physica B: Condensed Matter, vol. 406, no. 4, pp. 1034-1037, 2011.

[12] C. Tsai, K.-H. Li, J. C. Campbell, and A. Tasch, "Photodetectors fabricated from rapid-thermal-oxidized porous Si," Applied Physics Letters, vol. 62, no. 22, pp. 2818-2820, 1993.

[13] M. K. Lee, Y. H. Wang, and C. H. Chu, "High-sensitivity porous silicon photodetectors fabricated through rapid thermal oxidation and rapid thermal annealing," IEEE Journal of Quantum Electronics, vol. 33, no. 12, pp. 2199-2202, 1997.

[14] M.-K. Lee, Y.-C. Tseng, and C.-H. Chu, "A high-gain porous silicon metal-semiconductor-metal photodetector through rapid thermal oxidation and rapid thermal annealing," Applied Physics A: Materials Science and Processing, vol. 67, no. 5, pp. 541-543, 1998.

[15] S. J. Young, L. W. Ji, R. W. Chuang, S. J. Chang, and X. L. Du, "Characterization of $\mathrm{ZnO}$ metal-semiconductor-metal ultraviolet photodiodes with palladium contact electrodes," Semiconductor Science and Technology, vol. 21, no. 10, pp. 15071511, 2006.

[16] S. H. Abud, Z. Hassan, and F. K. Yam, "Fabrication and characterization of metal-semiconductor-metal photodetector based on porous InGaN," Materials Chemistry and Physics, vol. 144, no. 1-2, pp. 86-91, 2014.

[17] A. Ramizy, Z. Hassan, and K. Omar, "Porous silicon nanowires fabricated by electrochemical and laser-induced etching," Journal of Materials Science: Materials in Electronics, vol. 22, no. 7, pp. 717-723, 2011.

[18] A. F. Abd Rahim, M. R. Hashim, M. Rusop, N. K. Ali, and R. Yusuf, "Room temperature $\mathrm{Ge}$ and $\mathrm{ZnO}$ embedded inside porous silicon using conventional methods for photonic application," Superlattices and Microstructures, vol. 52, no. 5, pp. 941-948, 2012.

[19] K. Behzad, W. M. M. Yunus, Z. A. Talib, A. Zakaria, and A. Bahrami, "Effect of preparation parameters on physical, thermal and optical properties of n-type porous silicon," International Journal of Electrochemical Science, vol. 7, no. 9, pp. 8266-8275, 2012.

[20] H. R. Abd, Y. Al-Douri, N. M. Ahmed, and U. Hashim, "Alternative-current electrochemical etching of uniform porous silicon for photodetector applications," International Journal of Electrochemical Science, vol. 8, no. 9, pp. 11461-11473, 2013.

[21] B. E. B. Al-Jumaili, Z. A. Talib, L. Y. Josephine et al., "The correlation of blue shift of photoluminescence and morphology of silicon nanoporous," AIP Conference Proceedings, vol. 1733, Article ID 020019, 2016.

[22] P. R. Berger, “MSM photodiodes," IEEE Potentials, vol. 15, no. 2, pp. 25-29, 1996. 
[23] K. Bourenane, A. Keffous, and G. Nezzal, "Electrical properties of Schottky diode $\mathrm{Pt} / \mathrm{SiC}$ and $\mathrm{Pt} /$ porous $\mathrm{SiC}$ performed on highly resistif p-type 6H-SiC," Vacuum, vol. 81, no. 5, pp. 663668, 2007.

[24] J. M. Perez, J. Villalobos, P. McNeill et al., "Direct evidence for the amorphous silicon phase in visible photoluminescent porous silicon," Applied Physics Letters, vol. 61, no. 5, pp. 563565, 1992.

[25] D. Dimova-Malinovska and M. Nikolaeva, "Transport mechanisms and energy band diagram in $\mathrm{ZnO}$ /porous $\mathrm{Si}$ lightemitting diodes," Vacuum, vol. 69, pp. 227-231, 2003.

[26] A. Chouket, B. Cherif, N. Ben Salah, and K. Khirouni, "Optical and electrical properties of porous silicon impregnated with congo red dye," Journal of Applied Physics, vol. 114, no. 24, Article ID 243105, p. 6, 2013.

[27] N. M. Ahmed, Z. Hassan, N. Alhardan et al., "Porous silicon based violet-UV detector," in Proceedings of the International Conference on Nanotechnology-Research and Commercialization (ICONT 2011), vol. 1502, no. 1 of AIP Conference Proceedings, pp. 196-210, Sabah, Malaysia, June 2011.

[28] N. Naderi and M. R. Hashim, "Porous-shaped silicon carbide ultraviolet photodetectors on porous silicon substrates," Journal of Alloys and Compounds, vol. 552, pp. 356-362, 2013.

[29] H. I. Abdulgafour, Z. Hassan, F. K. Yam, K. Al-Heuseen, and Y. Yusof, "Enhancing photoresponse time of low cost $\mathrm{Pd} / \mathrm{ZnO}$ nanorods prepared by thermal evaporation techniques for UV detection," Applied Surface Science, vol. 258, no. 1, pp. 461-465, 2011.

[30] A. M. Selman and Z. Hassan, "Highly sensitive fast-response UV photodiode fabricated from rutile $\mathrm{TiO}_{2}$ nanorod array on silicon substrate," Sensors and Actuators, A: Physical, vol. 221, pp. 15-21, 2015.

[31] Y. Takahashi, M. Kanamori, A. Kondoh, H. Minoura, and Y. Ohya, "Photoconductivity of ultrathin zinc-oxide films," Japanese Journal of Applied Physics Part 1-Regular Papers Short Notes \& Review Papers, vol. 33, no. 12, pp. 6611-6615, 1994.

[32] N. Gabouze, K. Ait-Hamouda, S. Ouendadji, K. Henda, and N. Saoula, "Electrical and optical characterizations of $\mathrm{TiC} /$ porous Si/Si structures," Superlattices and Microstructures, vol. 36, no. 1-3, pp. 87-94, 2004.

[33] R. J. Martín-Palma, R. Guerrero-Lemus, J. D. Moreno, and J. M. Martínez-Duart, "Determination of the spectral behaviour of porous silicon based photodiodes," Solid-State Electronics, vol. 43, no. 6, pp. 1153-1157, 1999.

[34] S. M. Sze, Physics of Semiconductor Devices, Wiley International Editions, New York, NY, USA, 2nd edition, 1981.

[35] A. V. Brodovoi, V. A. Brodovoi, V. A. Skryshevskyi, S. G. Bunchuk, and L. M. Khnorozok, "Photoelectric properties of metal-porous silicon-silicon planar heterostructures," Semiconductor Physics, Quantum Electronics \& Optoelectronics, vol. 5, pp. 395-397, 2002. 

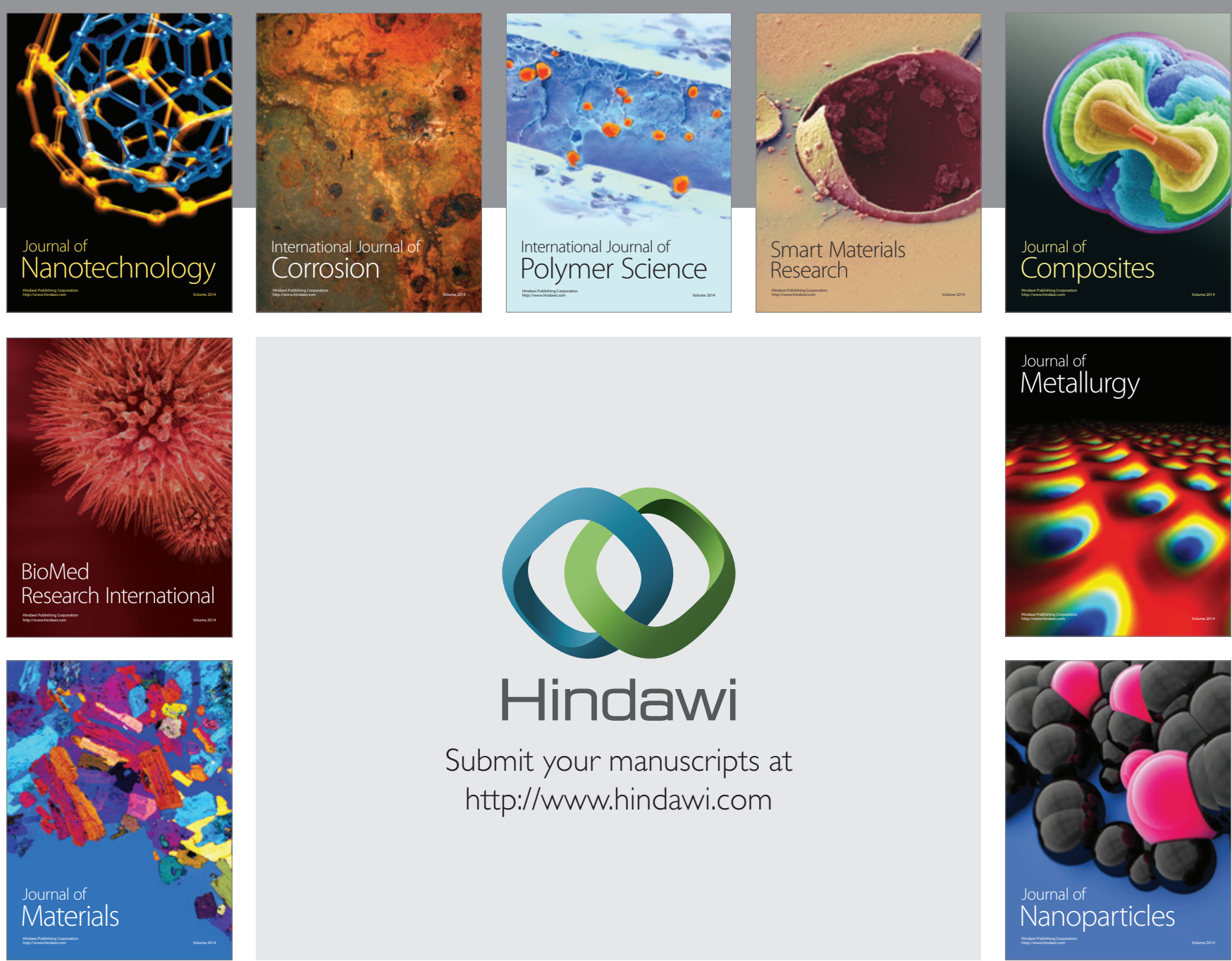

\section{Hindawi}

Submit your manuscripts at

http://www.hindawi.com

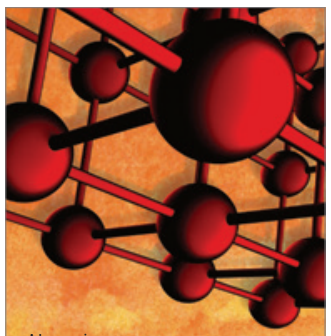

Materials Science and Engineering
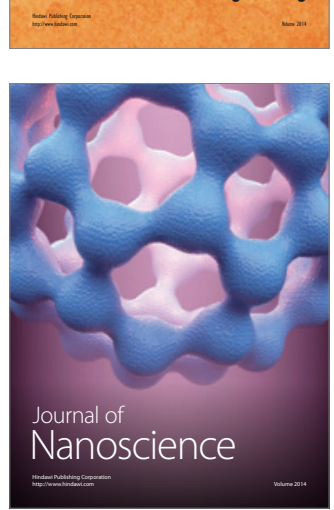
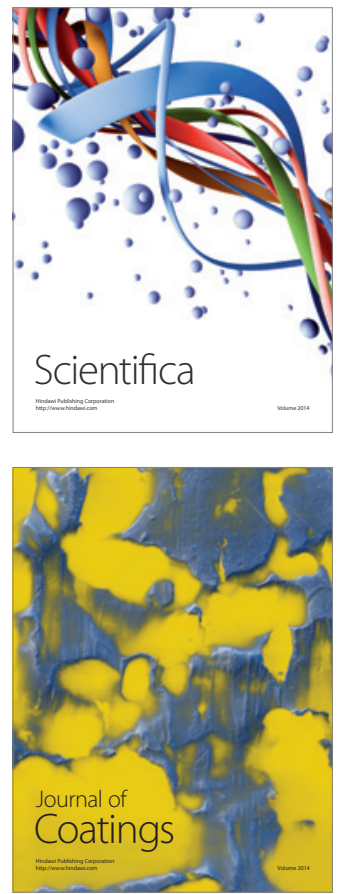
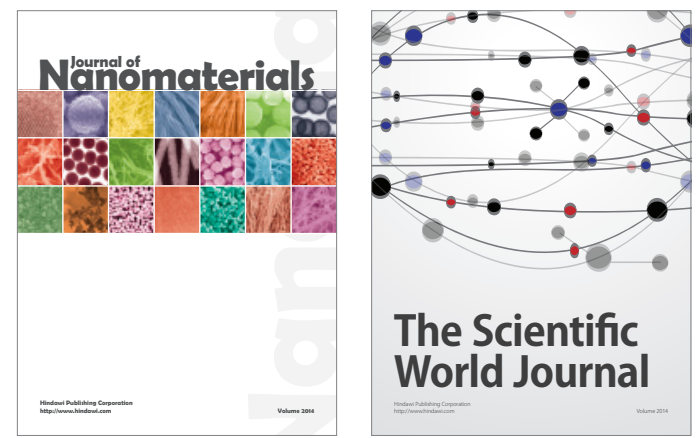

The Scientific World Journal
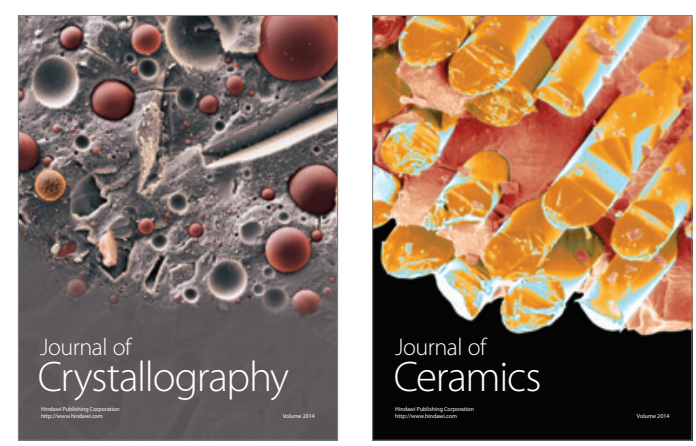
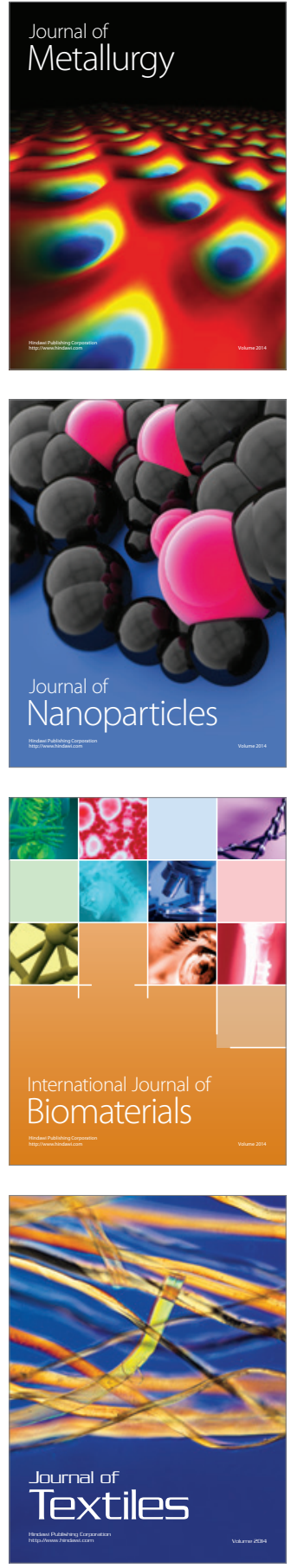